\title{
Monitoring Strategy for an Energy Efficient School Building
}

\author{
Boros Iosif, Nagy-Gyorgy Tamas, Florut Codrut, Dan Daniel
}

\begin{abstract}
The paper presents some aspects related to an energy efficient school building in Romania, designed in a moderate seismic zone, in which both the passive house concept and the renewable energy solutions are applied in order to optimize the maintenance cost and the global cost of the investment. In order to improve the real-time energy consumption of the building and to analyse the internal climate parameters, a complex monitoring system was planned and its main components are also presented.
\end{abstract}

Keywords-school, energy efficiency, monitoring system,
detailing

\section{Introduction}

In Romania there are just a few energy efficient buildings, the number of such constructions that are being designed currently is much lower than is the Western European average. Moreover, even less constructions exist in which the comfort and the energy consumption are both measured. Obviously, such types of residential houses and low-energy buildings exist in Romania, but they are not documented or certified and their parameters cannot be followed.

Energy efficient school buildings, according to the authors best knowledge, have been built only in developed countries, like Germany, Austria, Great Britain, France and the USA, and their number is about 80 [1]. In 2014, the possibility to build a school in Romania using the energy efficient concept arose. From the eight-person design team, four have had experience in the design of passive houses. In the first step of the analysis, the construction and maintenance costs of the proposed building was considered, comparing a conventional and an energy efficient built version. As expected, the preliminary results showed that, with higher initial investment, the maintenance costs can be reduced significantly (Fig. 1), which for the case of a long-term investment, such as a school, represents a very important issue. The payback period is roughly equal to the expected value of energy rehabilitation in Romania [2]. The initial investment of the school built in traditional solution is approximately 511 EUR $+\mathrm{VAT} / \mathrm{m}^{2}$, while the energy-efficient version is about 565 EUR + $\mathrm{VAT} / \mathrm{m}^{2}$. This $10 \%$ difference, based on the calculus, could be recovered in 6 years by the reduction of the maintenance costs. This was the deciding factor that convinced the investor to choose an energy-efficient solution. The school is currently under construction. Hopefully, in the spring of 2016 the entire building will be completed, regularly and rigorously supervised by the design team.

Boros Iosif, Nagy-Gyorgy Tamss, Florut Codrut, Dan Daniel

Politehnica University Timisoara

Romania

\section{Functionalities and the adopted solutions}

The facility was very limited from architectural point of view (Fig. 2), as it had to adapt to local site conditions. This multi-purpose building has a simple and compact architecture, with a total area of $4000 \mathrm{~m}^{2}$ (four $1000 \mathrm{~m}^{2}$ storey). On the ground floor is the main entrance, a library, storage rooms, a dining hall for 200 students and a kitchen with a capacity of 500 meals/day. The first and second floors will have classrooms, laboratories and administration offices. The third floor has a hostel for 60 students, a recreation place and a room for the medical staff. Thus, the capacity of the school will be of 450 students, 65 teachers and auxiliary staff (Fig. 3).

In the structural design phase, in addition to energy efficiency requirements, the Romanian earthquake resistance requirements have also been taken into account. Since the building has 4 storeys, reinforced concrete frame structure was prescribed.

Regarding the calculation of the foundations, in addition to the economy and the construction period, the thermal insulating possibilities were also considered. Thus, reinforced concrete shallow foundation, beam-grid base foundation and base plate type foundation were analysed, the second of which proved to be the most appropriate.

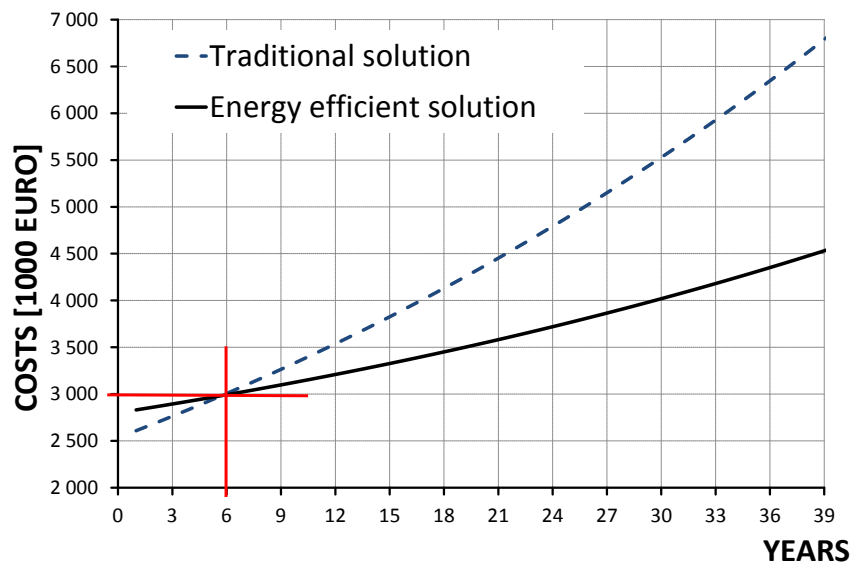

Figure 1. Lifespan - global cost comparison of the project for the two solutions 
Proc. of The Second Intl. Conf. On Advances in Civil, Structural and Mechanical Engineering - ACSM 2015

Copyright $(\odot$ Institute of Research Engineers and Doctors, USA .All rights reserved.

ISBN: 978-1-63248-074-3 doi: 10.15224/ 978-1-63248-074-3-72

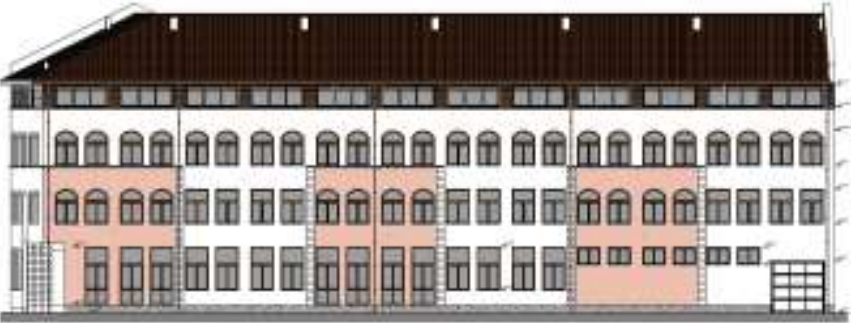

Figure 2. The facade of the school
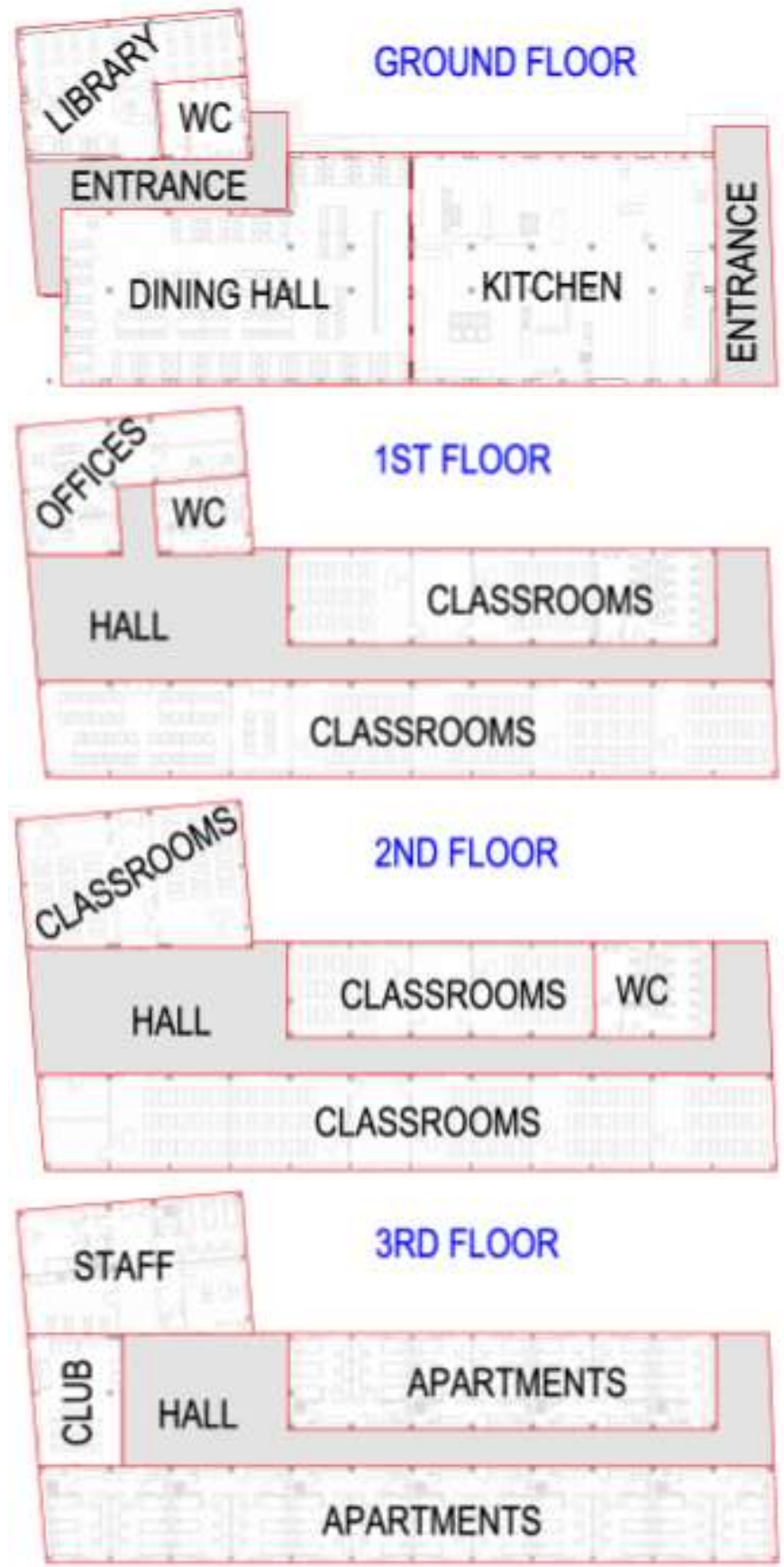

Figure 3. Floor plans and functionalities
The structure is covered by a pitched roof, with two firewalls. External masonry walls of $25 \mathrm{~cm}$ thickness are constructed of autoclaved concrete blocks, covered with $15 \mathrm{~cm}$ mineral wool insulation. The concrete slab of the ground floor has been insulated with $23 \mathrm{~cm}$ of extruded polystyrene (Fig. 4), while the attic slab with $20 \mathrm{~cm}$ thick mineral wool (Fig. 5).

While designing of the insulation of structural element, one of the main goal was to eliminate all the possible thermal bridges. The foundation beams were insulated up to $80 \mathrm{~cm}$ deep and $12 \mathrm{~cm}$ thick thermal insulation at the vertical outer perimeter (Fig. 6). These insulations are placed continuous on the exterior side of the ground floor wall's supporting beams, connected to the walls and floor insulation, without interruption (Fig. 7). This solution seriously decreases the temperature variations below the building and thus the heat loss to the ground will be minimal.

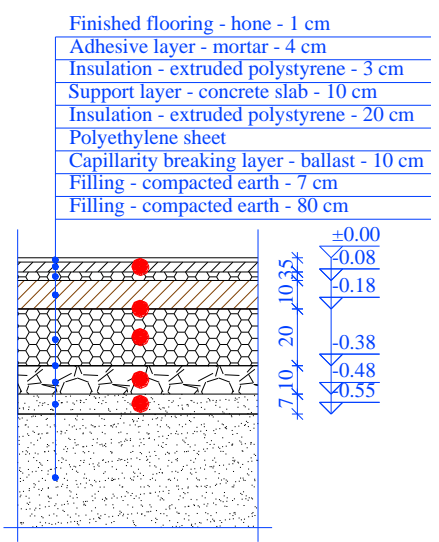

Figure 4. Specific detail for the ground floor slab

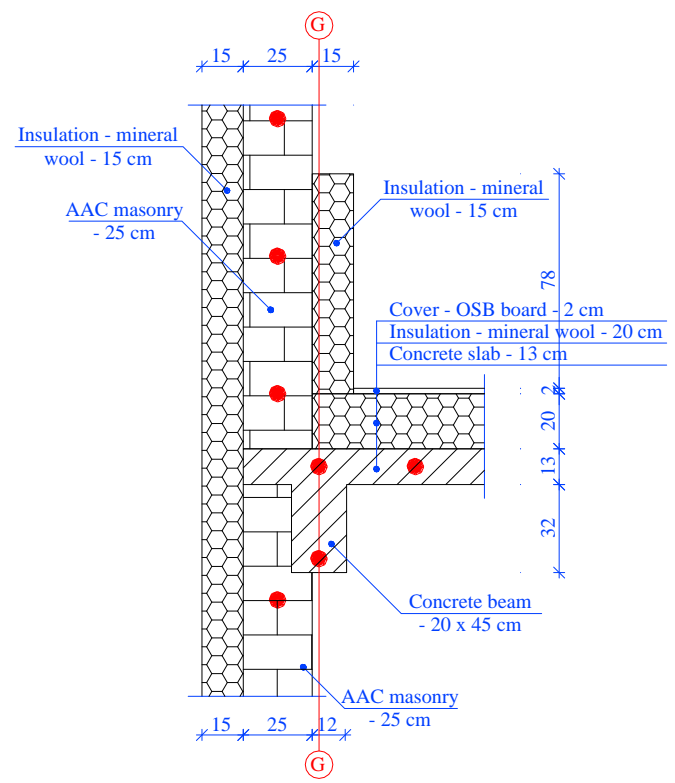

Figure 5. Detail for attic slab blind wall 
Proc. of The Second Intl. Conf. On Advances in Civil, Structural and Mechanical Engineering - ACSM 2015

Copyright $\odot$ Institute of Research Engineers and Doctors, USA .All rights reserved.

ISBN: 978-1-63248-074-3 doi: 10.15224/ 978-1-63248-074-3-72

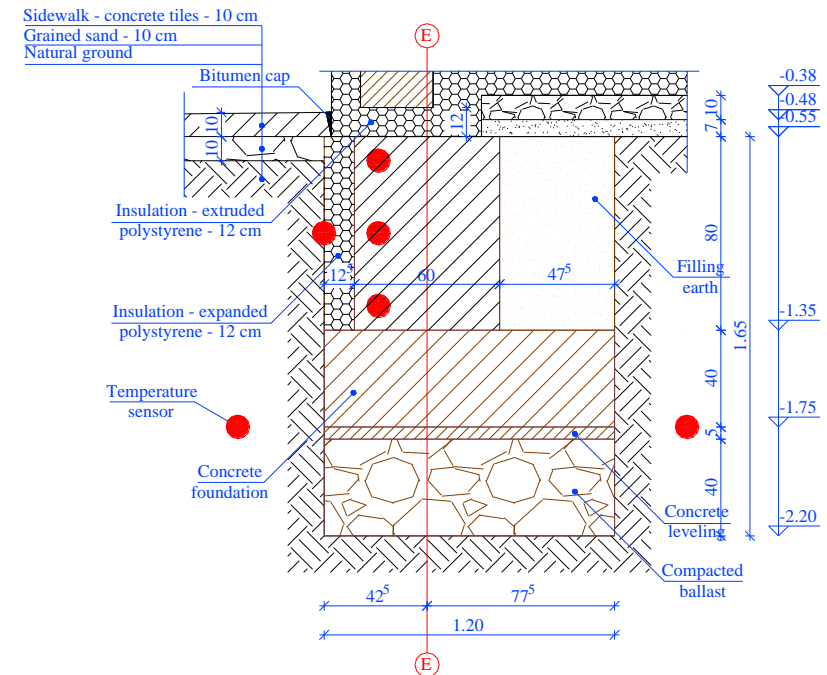

Figure 6. Detail for exterior foundation

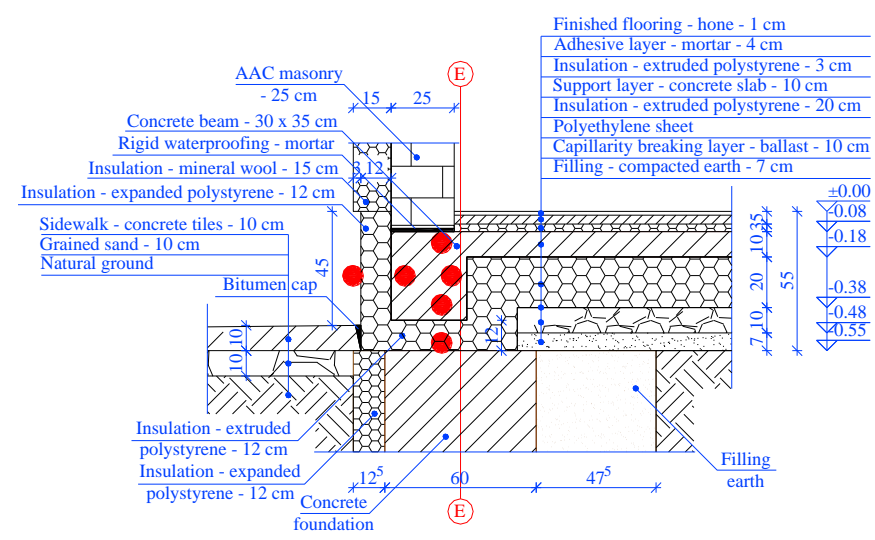

Figure 7. Thermal insulation detail for exterior footing beam and for the slab of the ground floor

On the ground floor there is a car shed which is unheated and has been considered as an exterior environment. The insulation between the heated area and the car shed presents problem areas that can only be limited but not eliminated in terms of thermal bridges. In order to limit the heat flux through the joints, extra insulation has been applied (Fig. 8 and 9).

The concrete columns, that delimit the two areas, intersect with the closing walls of the car shed which are insulated on the exterior side only to provide continuity to the façade, therefore an extra layer of insulation of $15 \mathrm{~cm}$ thickness has been put on the interior side of the closing wall. The exterior concrete columns that are in direct contact with the lower part of the slab thermal envelope have been insulated on their perimeter with a $5 \mathrm{~cm}$ thick thermal insulation to reduce the heat losses in the joint (Fig. 10 and 11).

Windows used in the building have triple glazing, PVC frame and the installation is designed with sealing belts to assure suitable air tightness. The external doors and windows are positioned in the thickness of the walls, so that the mineral wool insulation covers half of the width of the frame, thus reducing the formation of thermal bridges (Fig. 11). The adequate supply of natural light fundamental requirement for a school, the glass surface ratio is relative high, so this critical part of the building must seriously be considered.

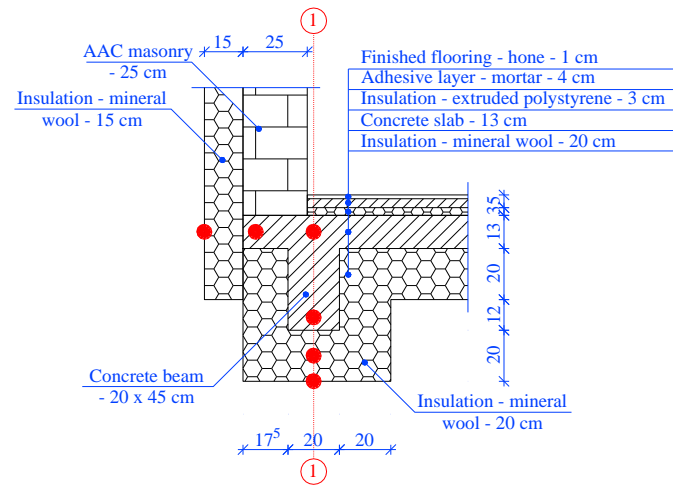

Figure 8. Detail for first floor exterior beam at the car shed

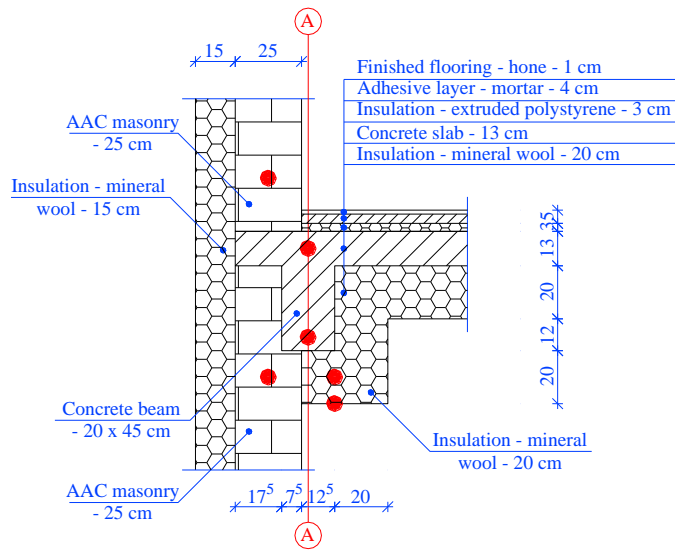

Figure 9. Detail for first floor exterior beam (current detail)

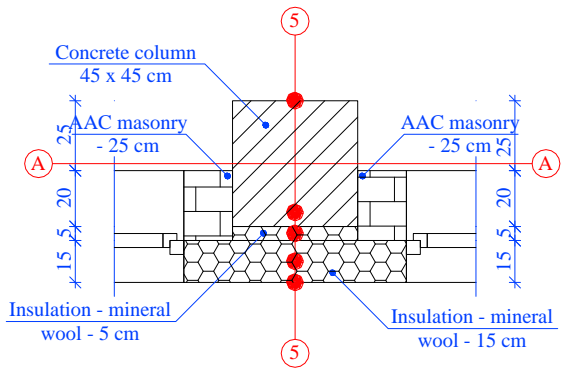

Figure 10. Detail for an intermediate column

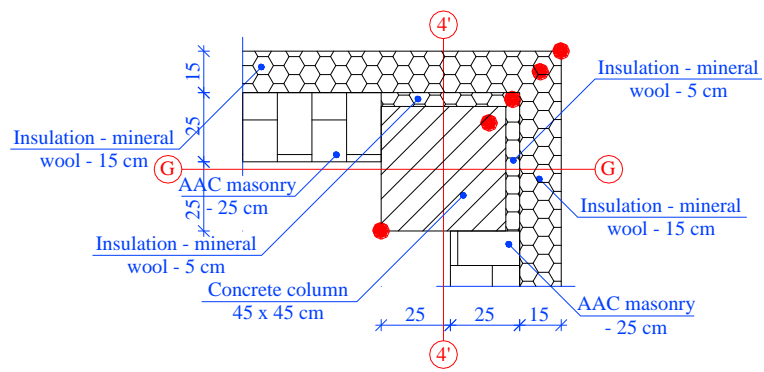

Figure 11. Specific detail for a column placed in a corner 
The Heat Ventilation and Air-Conditioning (HVAC) system is composed of heat pump convector fans for heating and cooling; also the domestic hot water demand will be solved with heat pumps. In addition, a heat recovery ventilation system is used and the ventilation rate is regulated by several $\mathrm{CO} 2$ sensors. The power supply of the kitchen equipment is represented by a natural gas-based system, which will also be the building heating reserve system as well.

The thickness of the thermal insulation was designed according to a detailed thermal calculation with accurate local climate data [3] in order to achieve a low energy consumption for heating, using the Passive House Planning Package (PHPP) [4], so that the heating energy is kept below 15 $\mathrm{kWh} / \mathrm{m} 2 /$ year. The resulted thicknesses of the insulation are significantly larger than the minimum required by the local legislation. However, it is known that these dimensions depend on other essential parameters as well, as orientation, air tightness, local climatic conditions, the occupancy rate, the amount of thermal bridges, solar gain, the type and/or performance and/or efficiency of used heat pumps and exchangers, the type of control system and last but not least, the users behaviour.

\section{Monitoring system}

Due to the fact that the functionality of the structure is quite complex and that by being a school it is discontinuously utilized, it cannot be classified in a typical building category, hence the calculated energy consumption may differ from the real values. In order for these differences to be measurable, a complex monitoring system has been developed. The objective of the measurements are multiple and the obtained parameters can be used at various evaluation levels. There are 3 involved parties, who are going to use, in different way, the available monitoring system.

The Designers can use the received data as follows: 1) to justify the preliminary calculations; 2) for calibration of the models in further design processes and to improve the calculation methods; 3) to increase energy efficiency of the specific building (cost optimization); and 4) to improve the comfort-feeling of the users. In such way the monitoring system will be/could be the link between the designer and the building.

The Investor (who in this case is the operator) may use the measured data as a very helpful tool that enables him to improve the real-time energy consumption, for better regulation and a proper response to the needs/demands of users.

The Users are key players in this equation, as their needs and expectations have to be fulfilled depending on their feedback, even though no access to the measured data has to be provided.

Using the monitoring system, several parameters will be measured. These could be sorted in 4 categories. In the first, the comfort and energy-efficiency parameters are included, which would contain: various temperatures (structural components, insulations, air, soil, cooling/heating water, heat pump water), humidity (indoor and outdoor), motion, window opening, solar radiation intensity and duration, occupancy (number of people), sound and light intensity and air tightness. The second category would be the measurement of the equipment's parameters, as further temperatures (heat exchangers, borehole, domestic hot water, the introduction and exhaust air), water consumption, air speed, power consumption (for various customers) and natural gas consumption. The third category would be parameter measurements dictated by medical considerations such as radon radiation, carbon dioxide $(\mathrm{CO} 2)$, formaldehyde $(\mathrm{CH} 2 \mathrm{O})$ vapour, nitrous oxide (N2O), nitrogen dioxide (NO2) and volatile organic compounds. The fourth category would be psychological measurements through questionnaire that follows the user's behaviour and behavioural changes, completed by both the students and their teachers also, thus evaluating the comfort feeling (air speed, humidity, temperature, overall comfort, etc.) and fulfilling of other requirements.

The location of the temperature sensors (represented by red dots on Fig. 4 to 11) has been conceived in order to provide real-time information on theoretically studied building details, in the same time measuring in many points throughout the structure, the outdoor and indoor climate. Since the distribution of the heat flux and temperatures in the joints depend on the geometric shape of the materials and their thermal properties, the sensors have been installed in the concrete, brick and insulation layers on all relevant sides. The connection between cables and sensors were protected with shrink tube, to ensure the proper operation even after concreting, brickwork or finishing/plastering phases.

All monitoring cables that have been installed in casted concrete, have been additionally provided with polyethylene pipes to protect the data flow from the sensors to the data logger. A number of 360 temperature sensors have been installed in every relevant section, of which 180 have been placed in ground, in foundations and in slab of the ground, in the floor, in the beams, columns and their thermal insulation. The rest are located in the masonry walls and in the roof structure. The measurements are recorded through several data acquisition unit (loggers). The processing of huge amounts of data will be implemented via an online platform. Development of this is already in progress. In the current schedule, the monitoring system will be operational in May 2016.

\section{Experience of the planning and implementation process}

In the present school building, the investor, in the same time, is the owner of the building, thus short- and long-term interests being easily compatible and convergent, since both the investment and the operating costs will be financed from the same source.

Therefore, the main interest of all interested parties (owner/investor) becomes the long-term cost minimization, a goal which forces the designers to identify the optimum solutions. If this interest agreement is missing, it's much 
harder to convince an investor of the short-term return of the initial additional costs.

It would be preferable that in the future, at least in the public sector for large investments, the submitted cost calculation to be done covering the entire life of the structure (life cycle cost assessment together with energy efficiency calculation).

An interesting aspect regarding this building, is represented by the fact that the design and construction cost of a traditional school and one with renewable concepts and energy-efficient solutions are almost identical. The substantial differences in the design phase is the added knowledge and in the execution phase the careful workmanship. Here must be emphasize the role of construction experts in spreading and promotion of similar or other energy-efficient solutions [5].

Perhaps the most important role have the technical advisors who had the contact with the potential investor from the initial phase. Decisions made in the initial design phase strongly conditions the sustainability parameters of technical solutions, even if is discussed about renovations or new buildings. In recognition of this, it is essential to pay much more attention to the decisions taken in the pre-planning stage [6].

\section{v. Conclusions}

In recent years, the energy-efficient buildings have gained more and more attention because of the economic and internal comfort benefits that they provide. Given the previously mentioned benefits, it is extremely important to mention that a school needs to create an environment which should be functioning in certain health parameters that would increase students' achievements and ability to maintain a high attention level. At the same time, the lower maintenance costs will allow improving the quality of education by redirecting/reallocating a part of the available budget.

This school has important research potential, because it is a multi-purpose building with non-continuous utilization, designed and executed using energy efficient concepts, details and construction methods, applying renewable energy systems. The use of a complex monitoring system finally will help the operator to make the best building parameters settings, taking into account the energy and health aspects, as well as the needs of the users.

Important information is going to be obtained from the measured parameters and data, which could be used in the design and execution phases of new school buildings, in the renovation of existing buildings, thus promoting environmental awareness in education, in schools as well as in other parts of society.

\section{Acknowledgment}

This work was supported by a grant of the Romanian National Authority for Scientific Research, CNDI-UEFISCDI; project number PN-II-PT-PCCA-2011-3.2-1214-Contract $74 / 2012$ and by the Sectoral Operational Programme Human
Resources Development POSDRU/159/1.5/S/137516 financed from the European Social Fund and by the Romanian Government, respectively.

\section{References}

[1] http://www.passivhausprojekte.de/ (Accessed in July 2015)

[2] Integrated Strategies and Policy Instruments for Retrofitting Buildings to Reduce Primary Energy Use and GHG Emissions (INSPIRE), Final Draft - Dec. 2014, ERACOBUILD

[3] http://www.meteonorm.com/ (data from 2014)

[4] Passive House Planning Package (PHPP), http://passiv.de/en/04_phpp/04_phpp.htm

[5] Zs. Nagy., L. Fülöp and Talja A., "Reconversion of Flat Buildings Administration: New Romanian Business Opportunities," Advanced Engineering Forum, vol. 8-9, pp. 621-630, Jun. 2013.

[6] H. Koukkari, E. Zukowska, C. Jose, P. Elguezabal, M. Sandra, V. Ungureanu, A. Ciutina, A. Dinca, E. Grodzicka, M. Chmielewski, H. Gervasio, P. Santos, L. Silva, L. Braganca, J. Andrade, C. Baniotopoulos, I. Zygomalas, V. Dehan, and O. Vassart, "Sustainable Building Project in Steel (SB-Steel)," Final Report RFSR-CT-201000027, 2014. (http://www.onesource.pt/sbsteel/site/)

About Author (s):

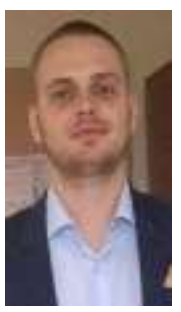

BOROS Iosif, PhD Student. Fields of interest: energy efficiency in buildings, monitoring systems, structural design, fire safety measures in buildings and project management.

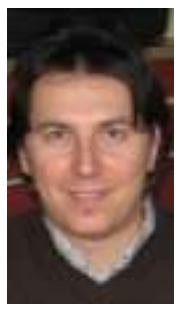

NAGY-GYORGY Tamas, Associate Professor, PhD. Fields of interest: FRP composites, structural health monitoring, structural design. Member of fib and ACI.

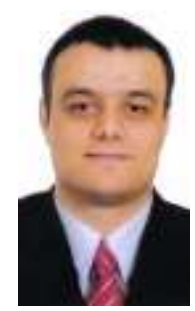

FLORUT Sorin-Codrut, Lecturer, PhD. Main fields of interest are Reinforced Concrete and the use of FRP composite for strengthening of RC structures.

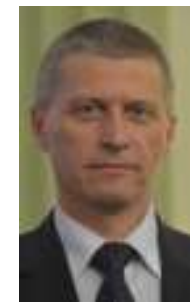

DAN Daniel, Professor, PhD. Main fields of interest energy efficiency of buildings, steel-concrete composite structure, rehabilitation of structures. Member of IABSE, fib, AICPS. 